\title{
Ultrastructural Characteristics of the Testis, Spermatogenesis and Taxonomic Values of Sperm Morphology in Male Ruditapes philippinarum in Western Korea
}

\author{
Jin Hee Kim ${ }^{1}$, Jae Seung Chung ${ }^{2}$ and ${ }^{\dagger}$ Ki-Young Lee $^{3}$ \\ ${ }^{1}$ Marine Eco-Technology Institute, Busan 608-830, Republic of Korea \\ ${ }^{2}$ Department of Urology, College of Medicine, Inje University, Busan 614-735, Republic of Korea \\ ${ }^{3}$ Department of Marine Biotechnology, Kunsan National Univerity, Kunsan 573-701, Republic of Korea
}

\begin{abstract}
Ultrastructural characteristics of the germ cells and accessory cells in testis during spermatogenesis and taxonomic values of mature sperm morphology of Ruditapes philippinarum were investigated by the transmission electron microscope and scanning electron microscope observations. The testis is the diffuse organ that consists of branching acini containing developing germ cells and accessory cells associated with spermatogenesis. The morphology of the spermatozoon is of the primitive type and is somewhat different to those of other bivalves. The morphologies of the sperm nucleus type and the acrosome shape of this species have a cylinderical type and a modified cone shape, respectively. As some ultrastructural characteristics of the acrosomal vesicle, the peripheral parts of two basal rings show electron opaque part, while the apex part of the acrosome shows electron lucent part. These characteristics of sperm belong to the family Veneridae in the subclass Heterodonta, unlike a characteristic of the subclass Pteriomorphia showing all part of the acrosome being composed of electron opaque part. In particular, a cylinder-like nucleus of the sperm is curved. The spermatozoon is approximately $48-51 \mu \mathrm{m}$ in length, including a long acrosome (about $2.40 \mu \mathrm{m}$ in length), a curved sperm nucleus (about $3.40 \mu \mathrm{m}$ in length), and a tail flagellum. The axoneme of the sperm tail shows a 9+2 structure.
\end{abstract}

Key words : Ruditapes philippinarum, Spermatogenesis, Germ cells, Accessory cells, Mature sperm ultrastructure

\section{INTRODUCTION}

Ultrastructures of germ cells and accessory cells associated with spermatogenesis and mature sperm ultrastructural features have been documented in many species of bivalve molluscs using both light and transmission electron microscopy (Healy, 1989, 1995; Gaulejac et al., 1995; Eckelbarger et al., 1990, Eckelbarger and Davis, 1996; Chung et al., 2007, 2010). It is well-known that spermatogenesis occurs through germ cell differentiations and accessory cells in acini of the testis. Above all, it is important to investigate the ultrastructure of the testis, the processes of germ cell differentiations by developmental stages and the morphology and ultrastructure of accessory cells during spermatogenesis to clarify the reproductive mechanism. In addition, it is important to study mature sperm ultrastructure.

To date, there have been many studies on $R$. philippinarum in Korea, Japan and other countries on aspects of reproduction, including the spawning season (Tanaka, 1954; Chung et al., 1994), reproductive cycle (Chung et al, 1994), and ovarian maturation and vitellogenesis during oogenesis (Choi et al., 2005). Despite this, there are still

\footnotetext{
Manuscript received 26 May 2013, received in revised form 8 June 2013, accepted 16 June, 2013

${ }^{\dagger}$ Corresponding Author : Ki-Young Lee, Department of Marine Biotechnology, Kunsan National Univerity, Kunsan 573-701, Republic of Korea. Tel. : +82-63-469-1832, E-mail : leekiy@kunsan.ac.kr

This is an Open Access article distributed under the terms of the Creative Commons Attribution Non-Commercial License(http:// creativecommons. org/licenses/by-nc/3.0) which permits unrestricted non-commercial use, distribution, and reproduction in any medium, provided the original work is properly cited.
} 
significant gaps in our knowledge regarding gametogenesis of this species. Little information is available on germ cells and accessory cells associated with spermatogenesis, and on special characteristics of mature sperm ultrastructure which is considered valuable tools in assessing phylogenetic and taxonomic problems of this species.

In the reproductive mechanism of spermatogenesis of bivalves, some authors (Eckelbarger et al., 1990; Eckelbarger \& Davis, 1996; Chung et al., 2010; Kang et al., 2012) reported that accessory cells (somatic cells) are associated with germ cell development during spermatogenesis as a source of nutrients to germ cells in the testis. Therefore, it is important to study some ultrastructural characteristics of the testis, germ cell differentiations and accessory cells by electron microscope observation. In bivalve molluscs, in particular, sperm ultrastructure is considered a valuable tool in assessing taxonomic and phylogenetic problems within the Bivalvia (Popham, 1979; Healy, 1989, 1995; Hodgson \& Bernard, 1986; Eckelbarger et al., 1990) and is especially useful when comparing closely related species (Popham, 1979). Thus sperm ultrastructures of bivalves are now widely used in taxonomic analysis (Healy, 1995; Chung et al., 2010).

Recently, sperm ultrastructure has been viewed in metazoa through the use of spermiocladistic analysis (Jamieson, 1991). Some authors (Popham, 1979; Healy, 1989) described that acrosomal morphologies of sperms have been used to organize bivalve subclasses, and the number of mitochondria in the sperm midpiece tends to be stable within any given family or superfamily. For that reason, it needs to study acrosomal morphology of the spermatozoon and the number of mitochondria in the sperm midpiece for taxonomic analysis of this species. For the study of taxonomic analysis of $R$. philippinarum which belongs to Veneridae in the subclass Heterodonta, information on sperm ultrastructure is needed for this important clade of bivalves. Therefore, the purpose of the present study is to describe germ cell differentiation and accessory cells associated with spermatogenesis, and to clarify some special features of the acrosomal vesicle in an acrosome of mature sperm ultrastructures as well as the number of mitochondria in the sperm midpiece for phylogenetic and taxonomic analyses of this species.

\section{MATERIALS AND METHODS}

Specimens of the male $R$. philippinarum were collected monthly at the intertidal and subtidal zones of Simpo, Jeollabuk-do, Korea from January to December 2004 (Fig. 1). A total of 50 male individuals were used for transmission/sanning electron microscope and scanning electron microscope observations.

\section{Transmission electron microscope observation}

For transmission electron microscope observations, excised pieces of the gonads were cut into small pieces and fixed immediately in $2.5 \%$ glutaraldehyde- $2 \%$ paraformaldehyde (0.1 M cacodylate buffer, $\mathrm{pH} 7.5$ ) for $2 \mathrm{~h}$ at $4^{\circ} \mathrm{C}$. After prefixation, the specimens were washed several times in the buffer solution and then postfixed in a $1 \%$ osmium tetroxide solution in $0.2 \mathrm{M}$ phosphate buffer ( $\mathrm{pH} 7.4$ ) for 1 hour at $4^{\circ} \mathrm{C}$. Specimens then were dehydrated in increasing concentrations of ethanol, cleared in propylene oxide and embedded in an Epon-Araldite mixture. Ultrathin sections of Epon-embedded specimens were cut with glass knives on a Sorvall MT-2 microtome and LKB ultramicrotome at a thickness of about $80-100 \mathrm{~nm}$. Tissue

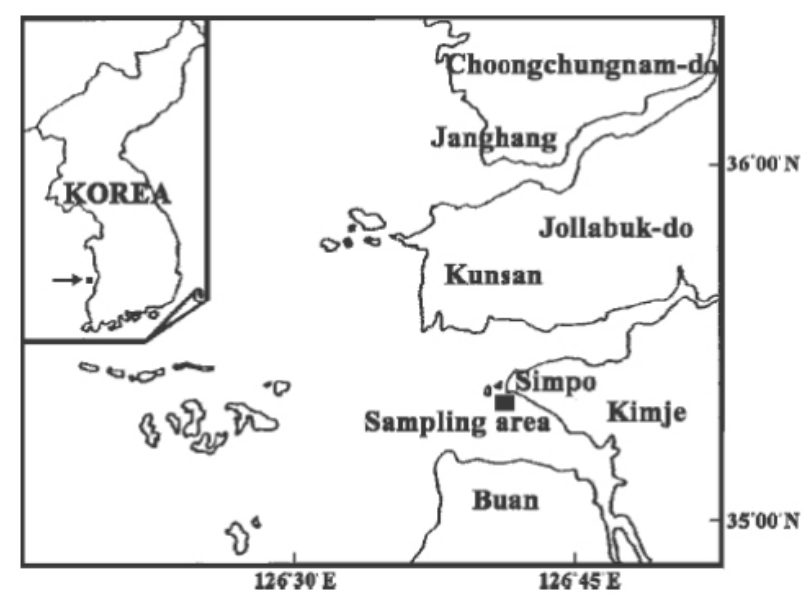

Fig. 1. Map showing the sampling area. 
sections were mounted on collodion-coated copper grids, doubly stained with uranyl acetate followed by lead citrate, and observed with a JEM $100 \mathrm{CX}-\Pi(80-\mathrm{KV})$ electron microscope.

\section{Scanning electron microscope observation}

A drop of sperm suspension was placed on a coverglass, prefixed with $2.5 \%$ glutaraldehyde and $2.5 \%$ paraformaldehyde in $0.1 \mathrm{M}$ cacodylate buffer $(\mathrm{pH} 7.5)$ at $4{ }^{\circ} \mathrm{C}$ for $15 \mathrm{~min}$, and post fixed with $1 \% \mathrm{OsO} 4$ for $10 \mathrm{~min}$, before rinsing with cacodyllate buffer. The specimens were dehydrated in a graded ethanol series, critical point dried, coated with gold, and observed under a scanning electron microscope (ISI-SS4D). In addition, after dehydration, some testes were freeze-fractured in liquid nitrogen, and then submitted to the same procedure described above.

\section{RESULTS}

\section{Position and ultrastructure of the testis}

The testes are irregularly arranged from the subregions of mid-intestinal glands in the visceral cavity to the reticular connective tissues of the foot. General morphology and structure of the testis of $R$. philippinarum is similar to that for the ovary (Choi et al., 2005). The testis is a diffuse organ that consists of a number of branching acini containing developing germ cells in a variety of stages. Each acinus is subdivided into a variable number of subcompartments that partially isolate groups of developing germ cells. Within each subcompartment, germ cells are distributed in a centripetal pattern from the acinus wall to the lumen. Spermatogonia are located nearest the inner wall of the acinus, while spermatocytes and spermatids are positioned closer to the lumen. Mature spermatozoa are largely confined to the central lumen of the acinus. Developing germ cells in adjacent subcompartments are partially segregated by myoepithelial cells and pleomorphic accessory cells. The outer wall of each acinus is composed of a discontinuous, single layer of flattened squamous myoepithelial cells which forms a partial barrier between the germinal epithelium and the hemocoel. The myoepithelial cells contain elongated nuclei and the occassional electron dense granules. A thin layer of collagenous connective tissue covers the hemocoelic surface of the myoepithelial cells. A thin basal lamina separates the epithelial cells from a layer of underlying accessory cells. The accessory cells (somatic cells), which are distributed within acinal subcompartments in close association with developing germ cells, are closely associated with all germ cell stages except the mature spermatozoa. Based on the volume of scattered condensed heterochromatin substances in the nucleus and the appearance of lysosomal-like dense granules in the cytoplasm of accessory cells classified by Eckerbarger et al. (1990), in this species, two types (first and second types) of accessory cells are observed in the inner wall of the acini during spermatogenesis. The first type of pleomorphic accessory cells (AC-I) contains a single slightly elongate nucleus containing scattered heterochromatin, and several mitochondria, a large quantity of

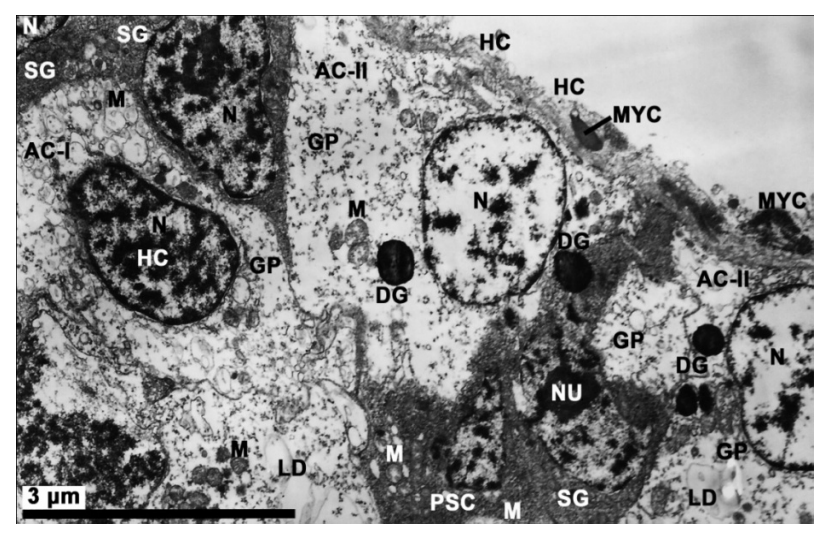

Fig. 2. A transmission electron micrograph showing the ultrastructure of the testis in male Ruditapes philippinarum. Note myoepithelial cells and haemocoel in the outer wall of the acinus and developing germ cells near the pleomorphic accessory cells (AC-I) and amoeboid assessory cells (AC-II) containing a large quantity of glycogen particle and lysosome-like dense granules in the inner wall of the acinus. Abbreviations: AC-I, pleomorphic accessory cell-I; AC-II, amoeboid accessory cell; DG, dense granule; GP, glycogen granule; HC, hemocoel; LD, lipid droplet; M, mitochondria; MYC, myoepithelial cell; N, nucleus; NU, nucleolus; PSC, primary spermatocyte; SG, spermatogonium. 
glycogen particles, and a few lipid droplets in the cytoplasm. However, it is difficult to find lysosome-like dense granules in the cytoplasm of AC-I. A second type of amoeboid accessory cells (AC-II) is observed in various locations throughout the acinus. This is an amoeboid-like form and contains a nucleus with patches of condensed heterochromatin, numerous cytoplasmic vesicles, small mitochondria, abundant glycogen deposits, and a few lysosomal-likedense granules, which are closely associated with developing germ cells. However, AC-II cells possess several lysosomal-like dense granules in the cytoplasm with degenerating germ (Fig. 2).

\section{Ultrastructure of germ cells and accessory cells} during spermatogenesis

Based on the testicular development and morphological characteristics of germ cells near accessory cells by electron microscopic observation, spermatogenesis occurs in the acini of the testis. The mature testis normally contains most stages of spermatogenesis, and the transition from spermatogonia to spermatozoon can be observed in one section. The process of spermatogenensis appears to be similar to other bivalves. Spermatogenesis occurs in the acini of the testis and can be divided into four stages: (1) spermatogonia, (2) primary and secondary spermatocytes, (3) spermatids, and (4) spermatozoa.

\section{1) Spermatogonia}

The spermatogonia are present along the acinus wall. In the first layer, several spermatogonia (approximately 6-7 $\mu \mathrm{m}$ in diameter) are large cells, irregularly shaped cells having little cytoplasm and a prominent spherical nucleus (about 3.3-3.8 $\mu \mathrm{m}$ in diameter) containing isolated patches of condensed chromatin. Their cytoplasm is largely devoid of organelles except for scattered mitochondria. At this time, each of the accessory cells (AC-I), which are located near the spermatogonia, contains chromatin substances in a prominent nucleus and a large quantity of glycogen particles, mitochondria and vacuoles in the cytoplasm (Fig. 3A).

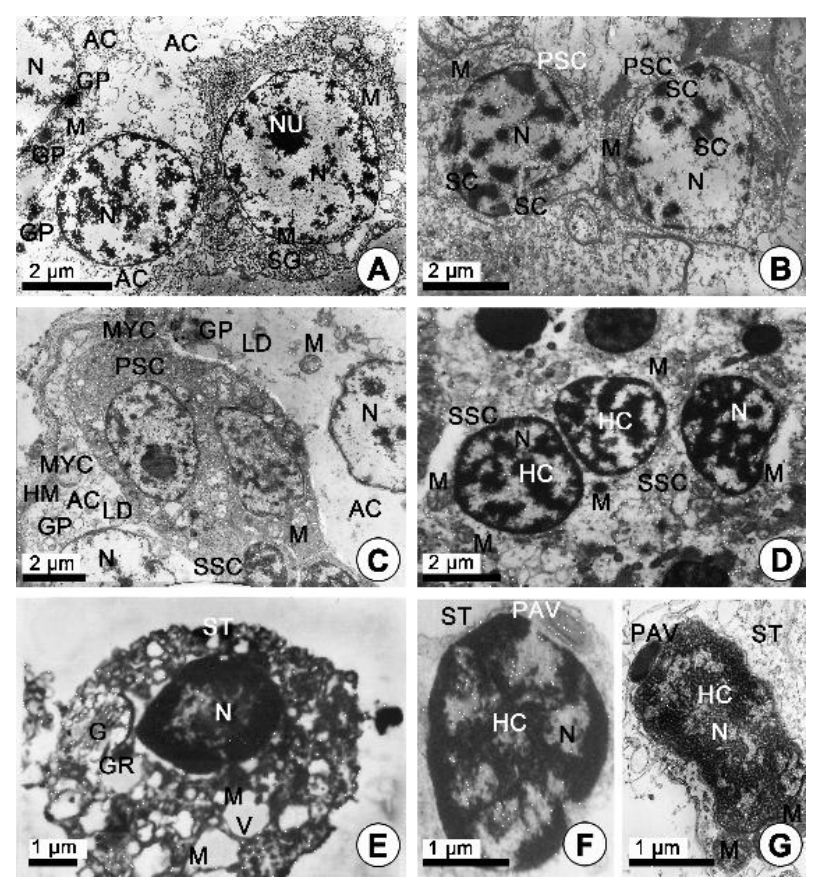

Fig. 3. Transmission electron micrographs of spermatogenesis in male Ruditapes philippinarum (A-G). (A), A spermatogonium and accessory cells. Note a spermatogonium containing a nucleolus in the nucleus and several mitochondria in the cytoplasm, and accessory cells containing large nucleus and glycogen particles and several mitochondria. (B), Primary spermatocytes and synaptonemal complexes. Note several synaptonemal complexes in the nucleus during the prophase of the primary maturation division and mitochondria $(\mathrm{M})$ in the cytoplasm of primary spermatocytes. (C), Primary spermatodcytes, secondary spermatocytes and accessory cells. Note primary spermatocytes and glycogen particles, lipid droplets, and mitochondria in the cytoplasm of the accessory cell in the inner layer of the acinus, and and myoepithelial cells and Haemocoel in the outer layer of the acinus. (D), Secondary spermatocytes. Note heterochromatins in the nucleus and several mitochondria in the cytoplasm of secondary spermatocytes. (E), A spermatid in the early stage of differentiation during spermiogenesis. Note the Golgi complex, granules near the nucleus. (F and G), Spermatids in the same stage. Note a proacrosomal vesicle just before the nucleus containing heterochromatins of the spermatid. Abbreviations: AC, accessory cells; G, Golgi complex; GP, glycogen particles; GR, granule; HC, heterochromatins; HM, Haemocoel; LD, lipid droplet; M, mitochondrion; MYC, myoepithelial cells; N, nucleus; NU, nucleolus; PSC, Primary spermatocyte; SC, synaptonemal complexes; SSC, secondary spermatocytes; ST, spermatid; PAV, proacrosomal vesicle. 


\section{2) Spermatocytes}

The spermatogonia differentiate into primary spermatocytes which resemble the former except for the larger diameter of their nuclei. In case of the spermatocyte stage, two stages of spermatocyte development, presumed to be the primary and secondary, can be observed in the acinus walls of the testis. Primary spermatocytes (approximately $5.5-6.5 \mu \mathrm{m}$ in diameter) are slightly smaller cells that are distinguished by nuclei (approximately $3.0-3.7 \mu \mathrm{m}$ ) with more abundant and more darkly staing chromatin. At this time, however, the nucleolus is no longer prominent. Zygotene/patchtene spermatocytes contain nuclei with more highly condensed chromatin and synaptonemal complexes formed as a result of pairing of homologous chromosomes during the zygotene stage of prophase I. The synaptonemal complexes in the nucleus appear in the prophase during the first maturation division. Several mitochondria appear in the cytoplasm, the cytoplasm reduced, so the nucleocytoplasm ratio increased. Cellular outlines are oval in shape (Fig. 3B). At this time, several pleomorphic accessory cells (AC-I), as a kind of somatic cells, are present near several primary and secondary spermatocytes, and a large quantity of glycogen particles, several mitochondria and a few lipid droplets are present in the cytoplasm of the accessory cells. In particular, the accessory cells are distributed within acinal subcompartments in close association with developing germ cells. However, the outer wall of the acinus is characterized by a discontinuous layer of thin squamous myoepithelial cells that forms a partial barrier between the hemocoels and developing germ cells (Fig. 3C). The secondary spermatocytes are rarely observed, probably due to the rapidity of the second meiotic division of the primary spermatocytes. They are irregular in shape and range from about $4-5 \mu \mathrm{m}$ in size. Spherical nucleus possesses scattered chromatin forming a network. The heterochromatin materials in the nucleus (approximately $3.5 \mu \mathrm{m}$ ) of the secondary spermatocyte are denser and more highly concentrated than those of the primary spermatocytes. At this time, several pleomorohic accessory cells (AC-I) are present near several secondary sper- matocytes, several mitochondria and a large quantity glycogen particles are present in the cytoplasm of the accessory cells (Fig. 3D).

\section{3) Spermatids}

The secondary spermatocyte is transformed into the spermatids by the secondary meiotic division. For convenience, spermiogenesis has been divided arbitrarily into two stages: the early and late stages Spermatids. In the early stage of spermatid (approximately $3.5-4.5 \mu \mathrm{m}$ in diameter), the nucleus is spherical and occupies the center of the cell. The nucleus (about $3.3-3.5 \mu \mathrm{m}$ in diameter) contains a scattered marginal heterochromatin, and the cytoplasm contains a number of mitochondria, the Golgi complex, granules which are formed by the Golgi complex, and vacuoles (Fig. 3E). Based on the characteristics of cell organelle differentiation, the processes of acrosome formation of the spermatids occur during spermiogenesis as follows. The morphology of the spermatid nucleus changes gradually during the differentiation of the spermatid. At this time, small granules are formed by the Golgi complex in the cytoplasm move to a position just in front of the nucleus, while mitochondria move to a position just behind the nucleus. After all, the morphologies of the spermatid nuclei were gradually elongated, and one or a few granules in the cytoplasm of the spermatid become a proacrosomal vesicle (Fig. $3 \mathrm{~F})$. The proacrosomal vesicle migrates to the presumptive anterior end the spermatid, where they coalesce to form a single electron-dense vesicle. The mitochondria become reduced in number but increase in size by mitochondrial fusion. The larger mitochondria form a close association with the nucleus and in many cases appears tightly apposed to the nuclear envelope. However, the shape of the nucleus is modified and becomes greatly elongated (Fig. 3G). A proacrosomal vesicle is modified and becomes a modified cone-like acrosomal vesicle on the nucleus. Thereafter, a cone-like acrosomal vesicle becomes an acrosome. And then the acrosome lying on the sperm nucleus become modified cone in shape (Fig. 4A). In the 


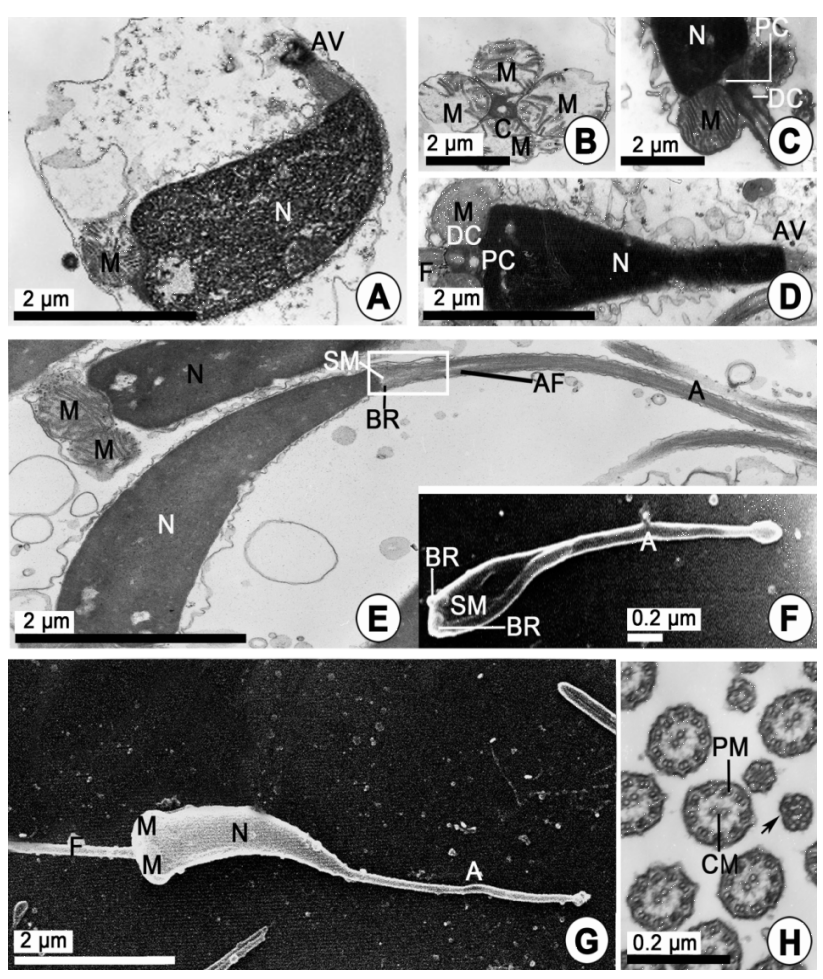

Fig. 4. Transmission and scanning electron micrographs of the spermatogenesis in male Ruditapes philippinarum (A-H). (A), A spermatid with the curved nucleus. Note an acrosomal vesicle on the curved nucleus $(\mathrm{N})$, the mitochondria beneath the nucleus. (B), Cross sectioned sperm midpiece. Note four mitochondria surrounding a pair of centrioles in the part of the sperm midpiece. (C and D), Spermatids in the late stage of spermiogenesis. Note the proximal centriole, distal centriole, mitochondria, and flagellum in the sperm midpiece beneath the sperm nucleus. (E), Spermatozoa with nuclei and mitochondria beneath the nuclei. Note an axial filament in the subacrosomal material in a long acrosomal vesicle being composed of basal rings. (F), SEM, the ultrastructure of an acrosomal vesicle in the acrosome. Note subacrosomal material in the basal rings of the acrosomal vesicle in an acrosome. (G), SEM, a mature spermatozoon. Note a long acrosome on the curved nucleus, mitochondria in the sperm midpiece, a long flagellum. $(\mathrm{H})$, Cross sectioned tail flagella. Note the axoneme of the sperm tail showing a $9+2$ structure (nine paire of pheripheral microtubules and a pair of central microtubule. TEM: Fig. 4A, 4B, 4C, 4D, 4E, 4H, SEM: Fig. 4F, 4G. Abbreviations: A, acrosome; $\mathrm{AF}$, axial filament; $\mathrm{AV}$, acrosomal vesicle; $\mathrm{BR}$, basal ring; CM, Central microtubule; DC, distal centriole; F, flagellum; M, mitochondrion; N, nucleus; $\mathrm{PC}$, proximal centriole; $\mathrm{PM}$, pheripheral microtubule; $\mathrm{SM}$, subacrosomal material. basal part of the nucleus, the mitochondria become reduced in number but increase in size by mitochondrial fusion. Posterior to the nucleus is the midpiece. This region consists of four spherical mitochondria surrounding a pair of triplet substructure centrioles. The cristae of each mitochondrion are randomly arranged (Fig. 4B). Larger mitochondria form a close association with the nucleus and in many cases appears tightly apposed to the nuclear envelope (Fig. 4C). At this time, of the two centrioles lying in the midpiece of the spermatozoon, the two centrioles, at right angles, show the classic nine triplets of microtubles. The proximal centriole laying the posterior fossa of the nucleus lies at $90^{\circ}$ to the sperm longitudinal axis. However, it appears to be unconnected to the nuclear envelope. The distal centriole lies parallel to the sperm longitudinal axis and forms the point of origin for flagellar axoneme (Fig. 4C, D). During the late spermatid stage, the sperm nucleus is long elongated, and the cytoplasm is greatly reduced, and so the rate of nucleo-cytoplasm is high. After the sperm nucleus (average $3.30 \mu \mathrm{m}$ long) is long elongated, an acrosomal vesicle is also gradually very elongated (average $2.26 \mu \mathrm{m}$ long). The acrosome has two regions of differing electron density. It is composed of electron-dense opaque parts (basal rings and lateral parts) and electron-lucent part (apex part). In particular, the axial filaments are present in the acrosomal lumen between two electron opaque and electron lucent parts (Fig. 4E). Subacrosomal granular materials are present in the subacrosomal space between the anterior invaginated part of the nucleus and the part of beginning of the axial filament in the acrosome (Fig. $4 \mathrm{E}, \mathrm{F})$. It is during late spermatid development that the axial filament of $R$. philippinarum appears, developing from a fibrous material within the central lumen of the acrosome.

\section{4) Spermatozoa}

After spermiogenesis, differentiation of spermatozoon is completed. Mature sperm morphology is primitive, as found in most bivalve species that undergo external 
fertilization. Mature sperm are approximately $48-51 \mu \mathrm{m}$ long. The head is about $6.20 \mu \mathrm{m}$ long and comprises a long, electron-dense nucleus (about $3.40 \mu \mathrm{m}$ ), with a posterior nuclear fossa, and an acrosome about $2.40 \mu \mathrm{m}$ long. The acrosomal vesicle is a long modified cone shape. The morphology of the sperm nucleus and the acrosomes of this species are of a curved cylindrical type and a long modified cone shape, respectively (Fig. 4E-G). The angles of the sperm nucleus of $R$. philippinarum are slightly curved $\left(25^{\circ}\right)$. At this time, a cross-sectioned tail flagellum shows that the axoneme is composed of a $9+2$ substructure (nine peripheral doublets surrounding a central pair of singlet microtubules) enclosed by a plasma membrane (Fig. 4H), and measures approximately $42-$ $45 \mu \mathrm{m}$ long (Fig. 4G).

\section{DISCUSSION}

Morphology and the ultrastructure of the testis during spermatogeneis in male $R$. philippinarum were similar to those of other bivalves, and spermatogenesis of this species also showed similar phenomena to those of other bivalves (Hodgson and Bernard, 1986; Eckelbarger et al., 1990; Kim, 2001; Kim et al., 2010a, b; Chung et al., 2007, 2010). However, in particular, morphology and the ultrastructure of the nucleus and acrosomal vesicle in an acrosome of mature spermatozoon of $R$. philippinarum were quite different, unlikely those of sperms of the species of Veneridae. Spermatogenesis occured through the interaction between germ cells and accessory cells in the acini. In this study, during the process of spermatogenesis of germ cells, the synaptonemal complexes in the nucleus of the primary spermatocyte appeared in the pachytene stage in the prophase during the first maturation division. Commonly, it was easy to observe that the pachytene stage in the primary spermatocyte was characterized by the presence of synaptonemal complexes in the nucleus. During spermatogenesis, the accessory cells, which were attached to germ cells in the acinus, provided nutrients for germ cell development (Eckelbarger et al.,
1990; Chung et al., 2007).

A few studies have documented that the ultrastructural features of testicular accessory cells (or follicle cells, auxiliary cells, and Sertoli cells) in bivalves, and most descriptions were too cursory to be useful in assessing homology. However, we believe that some attempt should be made to reassess and standarize the terminology used to describe these cells (Eckelbarger and Davis, 1996).

Eckelbarger et al. (1990) confirmed three types of somatic cells in three species of galeommatid bivalves. And they reported two types of accessory cells of three types of somatic cells: 1) the first, a pleomorphic "follicle cell" was confined to the inner wall of the testicular acinus and contained glycogen and lipid deposits; 2) the second, amoeboid cells were scattered throughout the acinus and contained lysosomal-like dense granules which are closely associated with developing sperm. Thus, two types of accessory cells have been described from the testis of a single bivalve species.

Regarding interactions between developing germ cells and accessory cells, to date, there have been some studies with respect to the presence or absence of cell junctions between accessory cells and developing germ cells in bivalves. Accessory cells were observed to be connected to adjacent germ cells via desmosomes in the testes of Scrabicullaria plana (Sousa et al., 1989). Tight junctions were reported in Pecten maximus (Dorange and Le Pennec, 1989). These findings showed that the interaction between germ cells and accessory cells. In this study, we have easily observed two types of accessory cells near early developing germ cells during spermatogenesis in the acini. In particular, a large quantity of glycogen particles (deposits) and a few lipid droplets were easily observed in pleomorphic accessory cells and amoeboid cells. In addition, amoeboid accessory cells contained a few lysosomal-like dense granules from the early stage of spermatogenesis (Fig. 2) to the period of germ cell degeneration after discharging of sperms. Therefore, it is assumed that two types of accessory cells may play some role in nutrition to developing germ cells during spermato- 
genesis. In particular, we supposed that amoeboid accessory cells may play some role in resorption of degenerating sperms after discharging of sperms for germ cell development. However, we could not find any phenomenon of resorption of germ cells during the period of this study.

In this study, unfortunately, we could not find any desmosome or tight junction between the accessory cell and the germ cell in the acinus in $R$. philippinarum. Henceforth, it should be investigated the ultrastrucure of the accessory cells for the observations of these findings mentioned above in detail.

Gaulejac et al. (1995) reported that in Pinna nobilis the auxiliary cells with pseudopodia-like projections between germ cells appeared to serve a resorptive function near the end of spermatogenesis. One common feature of these accessory cells is that they appear to have a phagocytic or resorptive function. In the present study, during the period of germ cell degeneration, we could find several lysosoamal-like dense granules in the cytoplasm of amoeboid accessory cells, however, we could not find any evidence associated with a phagocytic or resorptive function of the auxiliary cells reported by Gaulejac et al. (1995). Henceforth, we should investigate a function of the accessory cell during the period of germ cell degeneration.

Sousa et al. (1989) suggested that the Golgi complex may form only a single acrosomal vesicle in a manner similar to other molluscs. Some authors reported that proacrosomal vesicles were first observed in the spermatocyte stage in C. virginica (Eckelbarger \& Davis, 1996), and in the spermatid stage in Pecten maximus (Dorange \& Le Pennec, 1989).

In this study, however, in $R$. philipinarum, a proacrosomal vesicle appeared in the spermatid stage, and this vesicle developed to an acrosomal vesicle and became a mature acrosome. The above studies collectively showed that mechanisms of acrosomal vesicle formation in mollusc sperm were diverse and that no single mechanism characterizes bivalve sperm. Sperm ultrastructure of bivalves is considered a valuable tool in assessing taxonomic and phylogenetic problems within the Bivalvia (Franzén, 1970, 1983; Popham, 1979; Eckelbarger et al., 1990), and it is now widely used in taxonomic analyses (Healy, 1995): for example, 1) acrosomal morphology, and 2) the number of mitochondria in the sperm midpiece.

In this study, the types of sperm nuclei of $R$. philippinarum are the curved, long cylinderical type. Compared this species with other species of Veneridae, morphologies of the sperm nuclei in Saxidomus purpuratus, Dosinorbis japonicus and Mercenaria stinpsoni were of the curved, long cylinderical type, however, M. lusoria, C. sinensis and Notochione jedoensis are to the cylinderical type (Kim, 2001).

On the whole, the morphologies of the sperm nuclei in Veneridae species varied with the species. Kim (2001) reported that the angles of the sperm nucleus in the family Veneridae ranged from $0^{\circ}$ (Notochione jedoensis) to $45^{\circ}$ (Phacosoma japonicus) and $80^{\circ}$ (Mercenaria stinpsoni). In this study, the angles of the sperm nucleus of $R$. philippinarum was slightly curved $\left(25^{\circ}\right)$, however, exceptionally, that of this species was smaller than those of Phacosoma japonicus $\left(45^{\circ}\right.$ ) and $80^{\circ}$ (Mercenaria stinpsoni) reported by Kim (2001).

The sizes of sperm nuclei in Veneridae species ranged from $1.49 \mu \mathrm{m}$ (M. lusoria) to $7.80 \mu \mathrm{m}$ in length (Gomphina melanaegis).

In this study, the size of sperm nucleus of $R$. philippinarum was $3.40 \mu \mathrm{m}$ in length and smaller than that of P. japonicas (3.69 $\mu \mathrm{m}$ in length) and G. melanaegis (7.80 $\mu \mathrm{m}$ in length) reported by Kim (2001). According to the report of Kim (2001), of 8 species, in particular, the size of sperm nucleus of Meretrix lusoria was the shortest (1.49 $\mu \mathrm{m}$ in length), while G. melanaegis was the longest in length. Thus, morphologies and sizes of many species in Veneridae varied with the species. Therefore, the sizes of sperm nuclei could not be used in taxonomic analyses because morphological characteristics of sperm nuclei were irregular (Healy, 1995). Morphologies and sizes of the sperm acrosomes in Veneridae species 
varied with the species. The acrosomal morphology of the sperm head differs markedly among the species (Popham, 1979); the acrosome can be classified into five shapes: cone, long cone, modified cone, cap, and modified cap shapes. In Veneridae species, the acrosomal morphologies of the sperms of $R$. philippinarum were a modified cone shape. However, C. sinensis and Phacosoma japonicus were the cone shape, and in Saxidomus japonicus, Meretrix lusoria, Mercenaria stinpdoni, Notochione jedoensis were the cap shape (Kim, 2001). Compared with the morphology of the acrosomal vesicles in species of other families, the morphological, phylogenetical characteristics of acrosomal vesicles in $R$. philippinarum is the presence of largely modified cone shape during spermatogenesis. Therefore, we assume that the presence of a special acrosomal vesicle during spermatogenesis can be used as a key characteristic for identification of species of the genus Ruditapes, as seen in the family Veneridae. Kim (2001) reported that the sizes of sperm acrosomes in 8 species of Veneridae ranged from $0.39 \mu \mathrm{m}$ (Saxidomus purpuratus) to $1.13 \mu \mathrm{m}$ in length ( $G$. melanaegis). In this study, Compared this species with the size of sperm acrosome of Veneridae species (Kim, 2001), R. philippinarum is the longest $(2.40 \mu \mathrm{m}$ in length).

Judging from the morphologies of sperm nucleus and acrosomal shape in several bivalve species, the evolution of elongated sperm nuclei has been more highly correlated with the evolution of large, yolky eggs (Franzén, 1983). Therefore, in case of this species, it is supposed that the long curved cylinderical type of the sperm nucleus and largely modified cone shape of the acrosme are closely related with the acrosomal reaction for fertilization between the acrosomal structure of the sperm and features of the egg envelope. In this study, the most consistent feature of the sperm investigated in this work was that they had the axial filament in the acrosome as part of the apparatus making up the acrosome, it is assumed that the axial filament were closely related with the acrosomal reaction for fertilization between the acrosomal structure of the sperm and the egg envelope. However, the axial rod was not found in this species, therefore, structural characteristics of the acrosome in $R$. philippinarum show similar characteristics in Gomphina veneriformis of the family Veneridae (Chung et al., 2010).

Taxonomic value of sperm morphology and ultrastructure

Within the bivalves there is little variation in the fine structure of the tail and midpiece but great variation in the form of the nucleus and particularly the acrosome. In Veneridae, observations on the ultrastructure of the sperm of Gomphina veneriformis (Chung et al., 2010), and Phacosoma japonicus (Kim et al., 2011) show that differences in the acrosome and nuclear morphology exist between these three species. In case of the sperm nuclei, however, they cannot be used in taxonomic analyses because morphological characteristics and the sizes of sperm nuclei were irregular (Healy, 1995). However, we support the use of sperm ultrastructure (in particular, acrosomal vesicle) as an aid to bivalve identification. Despite the subtle differences in acrosome morphology that exist between closely related genera, the sperm ultrastructure from five subclasses of bivalve reveals that each subclass is characterized by a basic acrosomal morphology or position.

Recently, sperm ultrastructures of bivalves and acrosomal morphology are widely used in taxonomic analyses (Healy, 1995; Popham, 1979) because ultrastructures of the spermatozoa in 5 subclasses of the bivalves have some differences in the morphologies and positions of the acrosomes of the sperms (Popham, 1979).

The taxonomic value of sperm morphology at the level of species or genus in the Veneridae will be determined only through a broad, comparative study. To date, we have investigated the morphologies of the acrosomes in many families in two subclasses (Pteriormorphia and Heterodonta). From the results investigated, our investigations lead us to conclude that the Pteriomorphia and Heterodonta can be separated according to acrosome morphology and position. Hodgson \& Bernard (1986) 
described the morphological and characteristics of the acrosomal vesicles of the Heterodonta and the Pteriomorphia as follows: in general, the acrosomes of the Heterodonta are characterized by restriction of the electron-dense opaque material (region) to the base or lateral regions, while, the apex part of acrosome shows electron lucent materials (region). However, by contrast, the subclass Pteriomorphia all have acrosomes that are in the shape of a cone, albeit of varing dimensions, and that contain electrone-dense opaque material from the base to the tip. Thus, there are some differences in the ultrastructural characteristics between subclasses Heterodonta and Pteriomorphia.

To date, we have confirmed that acrosomes can be distinguisable those of the genuses and families by the morphologies and positions of the acrosomes. Taxonomically, $R$. philippinarum belongs to Veneridae in the subclass Heterodonta. In this study, this species in Veneridae in the Heterodonta have a common structural characteristics of the acrosomal vesicles showing the modified cone-like in shape, being composed of electron high density (opaque) materials to the base or lateral regions of basal rings, while the apex part of acrosome shows electron lucent materials (region) (Hodgson \& Bernard, 1986). From the results of observations by the ultrastructural characteristics of the acrosomal vesicle, we can confirm that $R$. philippinarum belongs to the Heterodonta, including the acrosomal vesicles showing the largely modified cone shape, as reported by Hodgson \& Bernard (1986). Therefore, our results coincide with those observed by Hodgson \& Bernard (1986). Therefore, for the identification of $R$. philippinarum in Veneridae in the subclass Heterodonta, we assume that sperm ultrastructure (in particular, the acrosomal vesicle) during spermatogenesis of bivalves can be considered a valuable tool in assessing taxonomic and phylogenetic problems. In addition, of sperm ultrastructures of bivalves, the number of mitochondria in the sperm midpiece is now widely used in taxonomic analyses (Healy, 1995). That is the reason that the number of mitochondria in the sperm midpiece tends to be stable within any given family or superfamily varying from a maximum of 14 in the mytiloid Modiotus difficilis (Dorozdov \& Reunov, 1986) to a minimum of 4 (common to many bivalve families) (Healy, 1989, 1995). Recently, some authors (Kim, 2001; Chung, 2007) described that the number of mitochondria in the midpiece of the spermatozoon is four in families Veneridae, Ostreidae, Solenidae, and Corbiculidae, while this number is five in the Arcidae, Mytilidae, Pinnidae, and Veneridae. Kim (2001) reported that the numbers of mitochondria in the midpiece of the sperms of the species in the family Veneridae are four in $R$. philippinarum, D. japonicus, M. stinppsoni and N. jedoensis, and five in S. purpuratus, M. lusoria and C. sinensis.

In the present study, we found that there are four mitochondria in the midpiece of the sperm in $R$. philippinarum. Sometimes, however, within one species, we assume that the number of mitochondria in the midpiece of the sperm show slight differences in number.

\section{ACKNOWLEDGMENTS}

The authors are grateful to Dr. Tae Hwhan Lee, the University of Michigan for helpful comments on the manuscript. This research was supported by Basic Science Research Program through the National Research Foundation of Korea (NRF) funded by the Ministry of Education, Science and Technology (2011-0027370). The authors also thank Coastal Research Center, Kunsan National University for supporting the research.

\section{REFERENCES}

Bernard RTF, Hodgson AN (1986) The fine structure of the sperm and spermatid differentiation in the brown mussel Pernaperna. South Africa Journal of Zoology 20:5-9.

Choi KH, Park GM, Chung EY (2005) Ovarian maturation in female Ruditapes philippinarum on the west coast of Korea. Dev Reprod 9:123-134.

Chung EY, Ryou DK (2000) Gametogenesis and sexual 
maturation of the surf clam, Mactra veneriformis on the west coast of Korea. Malacologia 42:149-163.

Chung EY, Chung CH, Kim JH, Park SW, Park KH (2010) Ultrastructures of germ cells and the accessory cells during spermatogenesis in male Gomphina veneriformis (Bivalvia: Veneridae) on the east coast of Korea 26:51-62.

Chung EY, Ryou DK, Lee JH (1994) Gonadal development, age and growth of the shortnecked clam, Ruditapes philippinarum (Pelecypoda: Veneridae), on the coast of Kimje. Kor J Malacol 19:38-54.

Chung EY, Kim EJ, Park GM (2007) Spermatogenesis and sexual maturation in male Mactra chinensis (Bivalvia: Mactridae) of Korea. Integr Bios 11:227-234.

Kang HW, Chung EY, Kim JH, Chung JS, Lee KY (2012) Germ cell differentiations during spermatogenesis and taxonomic values of mature sperm morphology of Atrina (Servatrina) pectinata (Bivalvia, Pteriomorphia, Pinnidae). Dev Reprod 16:19-29.

Dorange G, Le Pennec M (1989) Ultrastructural characteristics of spermatogenesis in Pecten maximus (Mollusca, Bivalvia). Inver Reprod \& Develop 15:109-117.

Drozdov TA, Reunov AA (1986) Spermatogenesis and the sperm ultrastructure in the mussel Modiolus difficillis. Tsitologiia 28:1069-1074.

Eckelbarger KJ, Davis CV (1996) Ultrastructure of the gona and gametogenesis in the eastern oyster, Crassostrea virginica. II. Testis and spermatogenesis. Mar Biol 127:89-96.

Eckelbarger KJ, Bieler R, Mikkelsen PM (1990) Ultrastructure of sperm development and mature sperm morphology in three species of commensal bivalves (Mollusca: Galeommatoidea). J Morph 205:63-75.

Franzén Å (1970) Phylogenetic aspects of the mophology spermatozoa and spermiogenesis in Baccetti B (ed): Comparative Spermatology. Accademia Nationale Dei Lincei, Rome 573pp.

Franzén Å (1983) Ultrastructural studies of spermatozoa in three bivalve species with notes on evolution of elongated sperm nucleus in primitive spermatozoa.
Gamete Research 7:199-214.

Gaulejac de J, Jenry M, Vicente N (1995) An ultrastructural study of gametogenesis of the marine bivalve Pinna nobilis (Linnaeus, 1758). II. Spermatogenesis. Journal of Molluscan Study 61:393-403.

Healy JM (1989) Spermiogenesis and spermatozoa in the relict bivalve genus Neotrigonia: relevance to trigonioid relationships, particularly Unionoidea. Mar Biol 103: 75-85.

Healy JM (1995) Sperm ultrastructure in in the marine bivalve families Carditidae and Crassatellidae and its bearing on unification of the Crasssatelloidea with the Carditoidea. Zool Sci 24:21-28.

Hodgson AN, Bernard RTF (1986) Ultrastructure of the sperm and spermatogenesis of three species of Mytilidae (Mollusca, Bivalvia). Gamete Res 15:123-135.

Jamieson BGM (1991) Fish Evolution and Systematics: Evidence from Spermatozoa. Cambridge University Press, Cambridge. pp.181-194.

Kim JH, Chung EY, Choi KH, Lee KY, Choi MS (2010a) Ultrastructure of the testis and germ cell development during spermatogenesis in male Crassostrea gigas (Bivalvia: Ostreidae) in western Korea. Kor J Malacol 26:235-244.

Kim JH, Chung EY, Choi KH, Park KH, Park SW (2010b) Ultrastructure of germcells during spermatogenesis and some characteristics of sperm morphology in male Mytilus coruscus (Bivalvia: Mitilidae) on the west coast of Korea. Kor J Malacol 26:33-43.

Kim JH (2001) Spermatogenesis and comparative ultrastructure of spermatozoa in several species of Korean economic bivalves (13 families, 34 species). Ph.D. thesis, Pukyung National University 161pp.

Ponurovsky SJ, Yakovlev YM (1992) The reproductive biology of the Japanese littleneck. Tapes philippinarum (A. Adams \& Reeve, 1850) (Bivalvia: Venerida). J Shellfish Res 11:265-277.

Popham JD (1979) Comparative spermatozoon morphology and bivalve phylogeny. Malacol Rev 12:1-20.

Sousa M, Corral L, Azevedo C (1989) Ultrastructural and 
JH Kim, JS Chung, K-Y Lee

cytochemical study of spermatogenesis in Scrobicula riaplana (Mollusca, Bivalvia). Gamete Res 24:393401.
Tanaka Y (1954) Spawning season of important bivalves in Ariake Bay III. Tapes philippinarum. Bull Jap Soc Sci Fish 19:1165-1167. 